\title{
Controversies of The Post-Lockdown New Normal - It May Not be Entirely Normal
}

\author{
KUOK HO DANIEL TANG \\ Environmental Science Program, Division of Science and Technology, BNU-HKBU \\ United International College, Zhuhai, China.
}

\begin{abstract}
Countries entered lockdown or partial lockdown due to mounting fear for the spread of COVID-19 and emerged from the restrictions with presumably new norms, often known as the 'new normal'. This commentary aims to examine whether the so-called 'new normal' qualifies as the new norms based on the definitions of social and cultural norms. The aim was achieved through reviewing pertinent literature comprising news articles, scholarly articles, government reports and websites centering on norms, COVID-19 new norms and their implications. It posits that social isolation does not align with the social nature of human and can be detrimental to the mind and body while social or physical distancing is situational. Unregulated, it does not quite constitute a norm for people to readily maintain social isolation, and social or physical distancing to a lesser degree. While mask-wearing is comparatively easier to adopt, its significance varies in different social and cultural settings. It is more normal to observe people wearing masks post-lockdown, particularly in Asia though experts' advice does encourage mask-wearing in certain western countries. Mask-wearing aptly qualifies as the new norm though this norm could last longer in certain societies, often strengthened by cultural norms. Similarly, high level of personal hygiene is still practiced often without coercion and is perceived to be normal at least for as long as the risk of COVID-19 is still present. It is thought that norms can be strengthened through interventions to promote behaviours that fit the norms.
\end{abstract}

\section{Introduction}

The raging Coronavirus Disease 2019 (COVID-19) has forced countries into lockdown or partial lockdown. With self-isolation, social-distancing, mask-wearing, hand-sanitizing, disinfection and movement control practiced during lockdown or

CONTACT Kuok Ho Daniel Tang $\$ daniel.tangkh@yahoo.com Environmental Science Program, Division of Science and Technology, BNU-HKBU United International College, Zhuhai, China.

\section{(c) (i)}

(C) 2021 The Author(s). Published by Enviro Research Publishers.

This is an Open Access article licensed under a Creative Commons license: Attribution 4.0 International (CC-BY).

Doi: http://dx.doi.org/10.12944/CRJSSH.4.1.02 
partial lockdown, countries which emerged from the restrictions continue to keep some, if not all, of the practices for fear of a new wave of COVID-19 infection. ${ }^{1}$ As long as COVID-19 remains a threat, self-isolation, social-distancing, mask-wearing and high level of personal hygiene are to stay as standard procedures. ${ }^{2}$ Prior to discussing whether these procedures are the 'new normal', it is crucial to understand the definition of normal.

Normal originates from the word 'norm' which is equated to the standards, expectations or even values imposed by a society, group or body on the individuals belonging to the entity. ${ }^{4} \mathrm{~A}$ norm can be prescriptive to promote desirable behaviours such as respect, or proscriptive to deter undesirable behaviours such as not committing crimes. ${ }^{3}$ Norms can be shaped by governments when establishing order or simply by one's internal motivations to live up to others' expectations. ${ }^{4}$ Norm is applied in a wide range of contexts such as social, cultural, legal, moral and linguistic ${ }^{5}$ (see Figure 1).

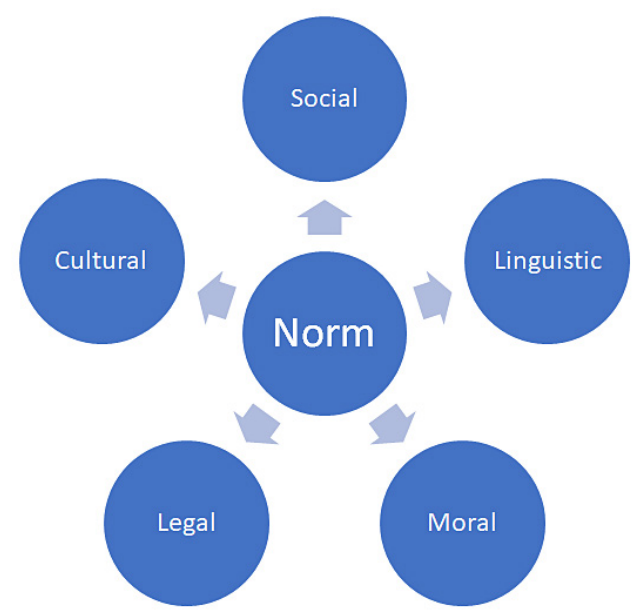

Fig. 1: The common types of norm

From the perspective of social norms, members of a society often develop informal understanding of how they should behave. ${ }^{6}$ Social norms therefore dictate behaviours in a particular circumstance. Put in the psychological context, social norms are the extents of manifestation of certain behaviours and approval of the behaviours by other members of a society. ${ }^{6}$ Cultural norms, on the other hand, are norms shaped by cultures. A culture can cast generally accepted expectations and rules upon members sharing the culture, for instance, the Asians tend to perceive calling parents by their names as disrespectful. ${ }^{7}$ A social norm can also be a cultural norm if members of the society share the same culture. Legal norms rely on the enforcement of rules and laws to govern social interactions and spell out the duties and rights of individuals under the power of a governing body. ${ }^{8}$ Moral norms are rules of morality for instance truthtelling, which may and may not be transformed into the binding legal norms. ${ }^{9}$ Brennan et al. stated that social and moral norms are fundamentally different in the sense that compliance to social norms is conditional due partly to normative expectations while moral norms demand unconditional commitment. ${ }^{7}$ Linguistic norms deal with the common linguistic characteristics defining the language used by a society or at a particular point of time. ${ }^{10}$

This commentary examines the post-lockdown new practices from the angles of social and cultural norms since there are apparent instances where the new practices have not been readily assimilated into certain societies and cultures, particularly physical distancing (also less accurately called social distancing in certain places) and mask-wearing. To a lesser extent, it also dissects the moral aspects of these new norms. It ultimately aims to present the controversy behind calling these practices 'new normal' and whether they qualify to be called 'new normal'.

\section{Method}

This commentary reviewed relevant literature about COVID-19 consisting of news articles from reliable sources, peer-reviewed journal articles, government reports and websites as well as conference papers to provide an overview of the post-lockdown practices in different countries. Literature search was conducted with search engines and journal databases, particularly Google, Google Scholar, Science Direct and Scopus, with keywords including COVID-19, lockdown, post-lockdown new norms and new normal. Countries included in the review were randomly selected based on the abundance of information from literature search. As COVID-19 lockdowns were mostly implemented in 2020 , the literature search was limited to materials published in 2020. For discussion of the new norms, various literature presenting the theoretical framework and empirical data of self-isolation, social/physical distancing, mask wearing and personal hygiene was referred without specifying the publication year. 
As this commentary mainly involved literature review, no primary data had been collected and analyzed.

\section{The Post-Lockdown 'New Norms'}

Countries emerging from lockdown or partial lockdown impose various rules on the public for containment of COVID-19. These rules are commonly perceived to be the new norms. In Malaysia, the common standard operating procedures or rules comprise wearing masks in the public, leaving contact details manually or electronically for contact tracing, keeping social distance, sanitizing and washing hands constantly and avoiding social gathering. ${ }^{11}$ In Australia, the public is advised to practice good hygiene and physical distancing, limit public gatherings and isolate oneself when needed..$^{12}$ The UK provides national guidance for the containment of COVID-19 post-lockdown in different scenarios such as meeting people, family and friends as well as returning to school, which revolves around isolation in instances of possible infection, social distancing, control of gatherings and wearing face covering under specific circumstances. ${ }^{13}$ The Canadian government also issues public advice on physical distancing, hand washing and hygiene practices, optional wearing of non-medical mask or face covering and quarantine in certain instances. ${ }^{14}$

\section{Self-Isolation}

Self-isolation is implemented via self-quarantine or self-imposed avoidance of social interactions. ${ }^{15}$ The definition of self-isolation may vary between countries and Australia differentiates isolation from quarantine by the criterion that isolation is meant for unwell individuals and quarantine is intended for well individuals, suspected to have COVID-19 or contacted people diagnosed with COVID-19. ${ }^{12}$ The UKencourages isolation if a person demonstrates symptoms of COVID-19 albeit mild. The duration of self-isolation varies from 7 days to 14 days. ${ }^{13}$ Self-isolation is mandatory in some countries and optional in others.

\section{Social-Distancing}

Like self-isolation, there is a lack of consensus on the definition of social-distancing. In Australia and Canada, this is called physical distancing where people should keep a safe distance of 1.5 to 2 $\mathrm{m}$ from each other and avoid close contacts. ${ }^{12,} 14$ The UK simply calls it staying safe outside home while the Malaysians generally call it social distancing. ${ }^{11,13}$
In Europe and the UK, social distancing actually encompasses self-isolation, quarantine, closure of educational institutions and workplaces, as well as prohibition of mass gathering. ${ }^{16}$ Social-distancing aims to reduce interpersonal interactions to lower the chances of infection by infectious diseases and is perceived to help curbing community transmission of infectious diseases. ${ }^{17}$

\section{Mask-Wearing}

Wearing mask has been encouraged but not mandated in certain countries as a means to slow down the spread of COVID-19 though there are controversies revolving around the effectiveness of mask-wearing. ${ }^{18}$ Countries such as Malaysia and Australia simply call this act the wearing of mask or face mask while the UK and Canada prefer to call this the wearing of face covering probably because mask tends to imply medical mask and it is not the only kind of face covering used. ${ }^{11,12,13,14}$ The resurgence of COVID-19 has made mask-wearing mandatory in more than 50 countries including South Korea, Spain and Germany. ${ }^{18}$

\section{Personal Hygiene}

Upkeeping of personal hygiene involves frequent handwashing, using hand sanitizers with certain alcohol concentration and minimizing contacts with eyes, nose and mouth. ${ }^{11,} 19$ Hygiene has been extended beyond the personal context to include sanitation of surfaces and objects as well as good ventilation. ${ }^{12,14}$ While handwashing is widely recommended to prevent COVID-19, there is a lack of consensus on the use of alcohol-based hand sanitizers. Frequent handwashing is associated with skin irritation and dermatitis, and alcohol-based hand sanitizers have been advocated as a substitute due to low sensitizing potential. ${ }^{20}$ However, there are also concerns on the variability of formulation of hand sanitizers and antimicrobial resistance. ${ }^{20}$

\section{Discussions}

\section{Self-Isolation as a 'New Norm'}

Intentional self-isolation can be regarded as a form of social isolation which deprives an individual of social connectedness. ${ }^{21}$ It is frequently perceived as detrimental to well-being. ${ }^{21}$ Smith et al. revealed that higher mortality among adults aged 50 and above was linked to high social isolation and low health literacy, thus, highlighting self-isolation as a health risk among adults. ${ }^{22}$ Swader found 
living alone and relational isolation contribute to loneliness. ${ }^{23}$ Social isolation is also identified as a domain of chronic stress in the Trier Inventory for Chronic Stress (TICS). ${ }^{24}$ The human longing for social relationships and social connection, as well as the detrimental effects of social disconnection have, in fact, been well documented. ${ }^{25}$ Steptoe et al. (2013) reported a weak yet significant correlation between social isolation and loneliness, the latter of which is a complex emotion of dissatisfaction and disengagement with varying intensity between individuals. ${ }^{26,27}$ Santini et al. found older people experiencing social isolation and loneliness tended to develop symptoms of depression and anxiety. ${ }^{28}$

Given that humans are inclined to be social, selfisolation is challenging unless it is guided by moral and legal norms. If not made mandatory, voluntary compliance to self-isolation could be difficult and could be affected by multiple factors. A study in Israel found compliance rate to self-quarantine affected by compensation for the wages lost and removal of such compensation reduced the compliance rate from $94 \%$ to $57 \% .{ }^{29} \mathrm{~A}$ Brazilian study revealed education, income, age and gender to affect the perception of self-isolation with most (39\%) participants perceiving social interaction to be affected and $24 \%$ perceiving their incomes to be impacted. The study demonstrated that perceived impact on income correlated significantly to perceived stress of a family. ${ }^{30}$ There have also been cases on the breaching of self-isolation globally. For instance, even with the possibility of facing prosecution, people under self-isolation were found to visit public places. ${ }^{31,32}$

Summing on the above, self-isolation especially a prolonged one, is unhealthy to general wellbeing especially that of the elderly and it is particularly challenging for people to remain in the state of self-isolation due to the social nature of humans. ${ }^{33}$ Unless with a strong moral sense, self-isolation does not readily become a new norm even in societies where legal norms are imposed. Albeit, the moral commitment to self-isolate could also be corroded when means of survival such as incomes is threatened. The frequent reporting of noncompliance to self-quarantine as shown in Table 1 testifies this.

Table 1: Noncompliance to self-quarantine in different countries

\begin{tabular}{llc}
\hline Country & Description & Source \\
\hline South Korea & $\begin{array}{l}\text { A non-compliance rate of 1.6 per 10,000 of self-quarantined individuals were } \\
\text { reported and the rate did not significantly improve with additional sanction. }\end{array}$ & 34 \\
Iran & $\begin{array}{l}\text { Poor compliance was reported among 20.5\% of the participants of a study } \\
\text { during the Persian New Year lockdown. }\end{array}$ & 35 \\
United States & $\begin{array}{l}\text { Tourists from Texas disregarded self-quarantine and mask-wearing order while } \\
\text { sight-seeing in the New Mexico during the COVID-19 outbreak. }\end{array}$ & 36 \\
Norway & $\begin{array}{l}\text { A cross-sectional study revealed low adherence (28\%) among individuals } \\
\text { without symptoms of COVID-19 requested to self-isolate. Overall adherence } \\
\text { to isolation requests was lower with the second and third waves. }\end{array}$ & 37 \\
United Kingdom & $\begin{array}{l}\text { Only 18\% of individuals with symptoms of COVID-19 underwent self-isolation } \\
\text { and only 11\% of individuals known to have contacted those with } \\
\text { COVID-19 were quarantined. }\end{array}$ \\
\hline
\end{tabular}

\section{Social-Distancing as a 'New Norm'}

In the UK, social distancing during COVID-19 was found to adversely impact mental health of the public, particularly those of the low-income category and a survey showed the participants' doubt in coping with social distancing and isolation over a longer term. ${ }^{39}$ Keeping of spatial distance between individuals depends on who the people are. It is naturally for people disliking each other to keep larger distances but it will be unnatural for people connected and are in good terms to distance each other. ${ }^{40}$ Social or physical distancing is against an experimental finding showing the tendency of people to maintain physical proximity to in-group members and to blend in with the crowd..$^{41}$ This crowding tendency is explained by the sharing of common identity-space 
which also confers a feel-good sensation during crowded events such as concerts, and a sense of security in the presence of in-group members. ${ }^{42}$

Countries such as Japan and Korea are experiencing a surge of COVID-19 cases with the easing of lockdown despite the looming threat of COVID-19 as new cases emerged at bars and nightlife destinations. ${ }^{43}$ Breaches of physical-distancing rules have been suspected to contribute to the resurgence of COVID-19 cases in Australia. ${ }^{44}$ This implies the propensity of people to gather, and the difficulty to sustain physical or social distancing with those to whom they are psychologically connected including strangers. ${ }^{41}$ In addition, an African study shows that the willingness to maintain physical distance was not encouraging among the Africans with a significant number of people still attending religious gatherings during the pandemic. ${ }^{45}$

Therefore, social or physical distancing does not seem to have readily evolved into a social norm during the post-lockdown era and it requires tremendous moral commitment and enforcement to maintain. Besides, like self-isolation, maintaining physical or social distances in many cultures and nations does not come by easily and is generally not a cultural norm. ${ }^{46}$ However, there are exceptions where social distancing is practiced due to religious reasons.

\section{Mask-wearing as a 'New Norm'}

Mask-wearing in certain cultures is stigmatized and associated with illnesses. This gives rise to the general fear for people wearing masks. This stigma prevents people from wearing masks as a control measure of epidemics. ${ }^{47}$ For the minorities, the stigma could intensify into assumptions of criminality. ${ }^{48}$ In addition, it was found that the socio cultural meaning associated with mask-wearing evolved constantly from positive during the era of Severe Acute Respiratory Syndrome (SARS) to negative post-SARS as it was against societal ideologies and cultural beliefs. ${ }^{49}$ Wearing of surgical masks, nonetheless, is widely accepted in Japan to protect oneself against various health threats and $72 \%$ of the masks manufactured in Japan were already worn at home prior to the swine flu in 2009. ${ }^{50}$ Besides, mask-wearing is also relatively common in Thailand and Vietnam and has been quickly adopted in Malaysia in combating the spread of COVID-19. ${ }^{15}$
In the US, some Americans may perceive maskwearing blacks as threatening, particularly when they wear homemade cloth masks and this could be a deterrent to wearing mask. ${ }^{51}$ However, a study found an increase in Americans wearing masks when the Centers for Disease Control and Prevention made such recommendation for containment of COVID-19 and this recommendation had greater effect on those trusting experts' advice. ${ }^{52}$ A survey showed the Americans wore masks more readily than the British with $73 \%$ American respondents saying yes to wearing face covering compared to $36 \%$ British respondents. 90\% Singaporean respondents actually said they wore masks during the pandemic. ${ }^{53}$

While social norm seems to have a great influence on mask-wearing for instance among the Japanese, cultural norm has a part to play with collectivist cultures prominent among the Asians more receptive to wearing masks than individualist cultures upholding individual freedom. ${ }^{46}$ As such, mask-wearing constitutes a new norm more readily in countries of collectivist cultures and in societies where masks are normally worn for protection against health threats, than in societies with predominating individualist cultures. In these societies, legal norms will need to be established. In fact, Singapore, being a collectivist society, also imposes fines on people not wearing masks. ${ }^{44}$ The new norm of wearing mask is foreseen to be transient and will wane upon the subsidence of the outbreak except in countries such as Japan where the norm has established.

\section{Personal Hygiene as a 'New Norm'}

Currently, there is a lack of studies on the behaviour of handwashing and sanitizing post-lockdown. A study among primary students in Wuhan, China found $42.1 \%$ of the students sampled practiced handwashing and $51.6 \%$ of them wore masks. These behaviours were affected by parents' occupation, educational background as well as students' gender and grade. ${ }^{54}$ Handwashing or sanitizing is among the easiest measures to prevent COVID-19 and do not require significant change of lifestyle. Therefore, practicing good personal hygiene, particularly hand hygiene quickly establishes as a social norm during the post-lockdown era with hand sanitizers readily available at business premises and public places. While personal hygiene is crucial to health and wellbeing irrespective of religion and culture, the manifestation of personal hygiene particularly hand 
hygiene may differ religiously and cultural norm does affect the practice of hand hygiene. ${ }^{55} \mathrm{~A}$ particular religion-related Sikh culture for instance, perceives hand hygiene as holy and essential and this group of Sikhs tends to practice handwashing with soap and water. ${ }^{55}$ While the social norm of frequent handwashing and sanitizing could weaken after the pandemic is over, the cultural norm will stay.

\section{Limitations and Implications}

This commentary provides a short review on the practices of self-isolation, social/physical distancing, mask-wearing and upkeeping of personal hygiene which have generally been regarded as the postlockdown new normal or norms, based on the definitions of the various facets of norm, particularly the social and cultural norms. It primarily aims to comment on whether these practices qualify as the 'new norms' without testing a theoretical framework. Therefore, no hypothesis has been framed. This commentary also faces the constraint of not covering all the literature related to these 'new norms' in the COVID-19 era due to the laborious effort needed to screen through the voluminous literature related to COVID-19 and the nature of a commentary to be concise. ${ }^{56,57}$ However, it has endeavoured to include the most pertinent ones.

Though limited, the commentary has the implication of identifying the post-lockdown practices which do not readily become the new norms. It opines that interventions can be designed to reinforce these practices. For instance, these interventions could aim to instil a sense of responsibility towards the community or to establish order via legislation and reinforcement, thus facilitating the shaping of moral and legal norms respectively. This commentary could also inspire hypotheses for future testing such as the higher acceptance of hand sanitization and a potential positive correlation between collectivist culture and mask-wearing.

\section{Conclusion}

Drawing from the above, people will practice selfisolation and social distancing in the presence of external motivators such as the establishment of legal norms and the fear of an infection but the practices often quickly wane when enforcement is relaxed and fear diluted. Even when rules are in place, breaching of self-isolation and social distancing has been frequently reported as it falls short of being a social and cultural norm generally. These new norms are thought to be short-lived as they are against human psychological longing for connectedness and prolonged self-isolation especially is unhealthy to a person mentally and psychologically. As for mask-wearing and stringent personal hygiene, these practices were quickly adopted due to social pressure and expectation, and have been continued post lockdown, which aligns with the 'new normal'. Mask-wearing is increasingly made mandatory and is more readily adopted in countries of collectivist cultures than those of individualist cultures. There is concern of stigmatization of the minorities who wear masks during the COVID-19 pandemic. This new norm will remain as a social and cultural norm in societies which commonly use masks for health protection but the social norm will wane in societies that attach negative meanings to wearing masks. Handwashing or sanitizing to maintain personal hygiene is relatively easy to practice and is likely to remain as the real new norm. This practice is strengthened by cultural norm and is deemed to probably be the most common and lasting new norm. In many instances, a norm can be strengthened particularly when there is increasing adoption of or compliance to a particular practice. ${ }^{58}$ The sight of people wearing masks and washing hands can serve as a motivation or force for others to follow. Therefore, interventions to sustain certain positive behaviours in combating COVID-19 can be designed.

\section{Acknowledgement}

The author wishes to acknowledge BNU-HKBU United International College for providing the resources needed for the completion of this article.

\section{Funding}

The author(s) received no financial support for the research, authorship, and/or publication of this article.

\section{Conflicts of Interests}

No conflicts of interests have been identified.

\section{Ethical approval}

This study does not require ethical approval. 


\section{References}

1. Tang, K. H. D. (2020). Movement control as an effective measure against Covid-19 spread in Malaysia: an overview. Journal of Public Health. https://doi.org/10.1007/s10389-02001316-w

2. CMS. (2020). Planning for the "new normal" post lockdown - what are the legal implications for employers? Retrieved May 14, 2020 from https://www.cms-lawnow. com/ealerts/2020/05/planning-for-the-newnormal-post-lockdown-what-are-the-legalimplications-for-employers.

3. Horne, C. (2018). Norms. Retrieved May 14, 2020 from https://www.oxfordbibliographies. com/view/document/obo-9780199756384/ obo-9780199756384-0091.xml\#.

4. Mollborn, S. (2009). Norms about nonmarital pregnancy and willingness to provide resources to unwed parents. Journal of Marriage and Family, 71(1), 122-134.

5. Dungan, J., Waytz, A., \& Young, L. (2014). Corruption in the context of moral trade-offs. Journal of Interdisciplinary Economics, 26(1-2): 97-118. https://doi. org/10.1177/0260107914540832

6. Davidson, L. J., \& Kelly, D. (2018). Minding the gap: Bias, soft structures, and the double life of social norms. Journal of Applied Philosophy n/a, (n/a). https://doi.org/10.1111/ japp.12351

7. Brennan, G., Eriksson, L., Goodin, R.E., \& Southwood, N. (2013). Explaining norms ( $1^{\text {st }}$ ed.). Oxford: Oxford University Press.

8. Lynch, R. A. (1997). Distinguising between legal and moral norms: A central problem in Habermas's between facts and norms. Philosophy Today, 41(Supplement), 67-72.

9. Harms, W., \& Skyrms, B. (2008) Evolution of moral norms. In: Ruse M (ed) The Oxford handbook of philosophy of biology ( $1^{\text {st }}$ ed.). Oxford: Oxford University Press.

10. White, M. J. (1979). Linguistic norms and norms in linguistics. Journal of Pragmatics, 3(1), 81-98. https://doi.org/10.1016/03782166(79)90007-9

11. Ministry of Health Malaysia, (2020). COVID-19: Social distancing guidelines for workplace, homes and individuals. Retrieved July 27, 2020 from http://covid-19. moh.gov.my/garis-panduan/garis-panduankkm/Annex_26_COVID_guide_for_Social_ Distancing_24032020.pdf.

12. Australian Government Department of Health. (2020). Coronavirus (COVID-19) health alert. Retrieved July 25, 2020 from https:// www. health.gov.au/news/health-alerts/ novel-coronavirus-2019-ncov-health-alert ?gclid=EAlalQobChMluOOPs7bn6gIVVQ 4rCh11_wgAEAAYASAAEgLky_D_BwE. Accessed 25 July 2020

13. Cabinet Office. (2020). Guidance - Staying alert and safe (social distancing). Retrieved July 25, 2020 from https://www.gov.uk/ government/publications/staying-alert-andsafe-social-distancing/staying-alert-and-safesocial-distancing-after-4-july.

14. Government of Canada. (2020). Physical distancing: How to slow the spread of COVID-19. Retrieved July 25, 2020 from https://www.canada.ca/en/public-health/ services/publications/diseases-conditions/ social-distancing.html.

15. Tang, K. H. D. (2020). A scoping review of studies on COVID-19. International Journal of Science and Healthcare Research, 4(2),205214

16. ECDC. (2020). Considerations relating to social distancing measures in response to COVID-19 - second update. Retrieved 28 July, 2020 from https://www.ecdc.europa.eu/ sites/default/files/documents/covid-19-socialdistancing-measuresg-guide-second-update. pdf

17. Wilder-Smith, A., \& Freedman, D. O. (2020). Isolation, quarantine, social distancing and community containment: pivotal role for old-style public health measures in the novel coronavirus (2019-nCoV) outbreak. Journal of Travel Medicine, 27(2). https://doi. org/10.1093/jtm/taaa020

18. Al Jazeera News. (2020). Which countries have made wearing face masks compulsory? Retrieved July 28, 2020 from https://www.aljazeera.com/ 
news/2020/04/countries-wearing-facemasks-compulsory-200423094510867.html.

19. Tang, K. H. D. (2020). A comparative overview of the primary Southeast Asian safety and health laws. International Journal of Workplace Health Management. https://doi. org/10.1108/IJWHM-10-2019-0132

20. Beiu, C., Mihai, M., Popa, L., Cima, L., \& Popescu, M. N. (2020). Frequent hand washing for COVID-19 prevention can cause hand dermatitis: Management tips. Cureus 12(4), e7506. https://doi.org/10.7759/ cureus.7506

21. Zavaleta, D., Samuel, K., \& Mills, C. T. (2017). Measures of social isolation. Social Indicators Research 131(1), 367-391. https:// doi.org/10.1007/s11205-016-1252-2

22. Smith, S. G., Jackson, S. E., Kobayashi, L. C., \& Steptoe, A. (2018). Social isolation, health literacy, and mortality risk: Findings from the English longitudinal study of ageing. Health Psychology, 37,160-169. https://doi. org/10.1037/hea0000541

23. Swader, C. S. (2018). Loneliness in Europe: Personal and societal individualismcollectivism and their connection to social isolation. Social Forces, 97(3), 1307-1336. https://doi.org/10.1093/sf/soy088

24. Schulz, P., Schlotz, W., \& Becker, P. (2004). Trierer Inventar zum chronischen Stress: TICS. Hogrefe.

25. Weir, K. (2018). Life-saving relationships. Monitor on Psychology, 49(3).

26. Steptoe, A., Shankar, A., Demakakos, P., \& Wardle, J. (2013). Social isolation, loneliness, and all-cause mortality in older men and women. Proceedings of the National Academy of Sciences of the United States of America, 110, 5797-5801.

27. Victor, C. R., Scambler, S. J., Bowling, A. \& Bond, J. (2005). The prevalence of, and risk factors for, loneliness in later life: A survey of older people in Great Britain. Ageing and Society, 25(6):357-375.

28. Santini, Z. I., Jose, P. E., York Cornwell, E., Koyanagi, A., Nielsen, L., Hinrichsen, C., ... Koushede, V. (2020). Social disconnectedness, perceived isolation, and symptoms of depression and anxiety among older Americans (NSHAP): a longitudinal mediation analysis. The Lancet Public Health,
5(1), e62-e70. https://doi.org/https://doi. org/10.1016/S2468-2667(19)30230-0

29. Bodas, M., \& Peleg, K. (2020). Self-isolation compliance in the COVID-19 era influenced by compensation: Findings from a recent survey in Israel. Health Affairs, 39(6), 936941.

30. Bezerra, A. C. V., da Silva, C. E. M., Soares, F. R. G., \& da Silva, J.A.M. (2020). Factors associated with people's behavior in social isolation during the COVID-19 pandemic. Ciência \& Saúde Coletiva 25(Suppl. 1), 2411-2421. https://doi.org/10.1590/141381232020256.1.10792020

31. BBC. (2020). Coronavirus: More than 9000 fines for lockdown breaches. Retrieved July 26, 2020 from https://www.bbc.com/news/ uk-52489943.

32. The Korea Herald. (2020). 10 indicated for breaching coronavirus selfisolation rule. Retrieved July 26, 2020 from http://www.koreaherald.com/view. php?ud=20200421000810.

33. Tomasello, M. (2014). The ultra-social animal. European Journal of Social Psychology, 44(3), 187-194. https://doi.org/10.1002/ ejsp. 2015

34. Ryu, S., Hwang, Y., Yoon, H., \& Chun, B. C. (2020). Self-Quarantine Noncompliance During the COVID-19 Pandemic in South Korea. Disaster Medicine and Public Health Preparedness, 1-4. https://doi.org/DOI: 10.1017/dmp.2020.374

35. Paykani, T., Zimet, G. D., Esmaeili, R., Khajedaluee, A. R., \& Khajedaluee, M. (2020). Perceived social support and compliance with stay-at-home orders during the COVID-19 outbreak: evidence from Iran. BMC Public Health, 20(1), 1650. https://doi.org/10.1186/ s12889-020-09759-2

36. Hay, A. (2020). Quarantine or not, tourists still flock to New Mexico. Reuters. Retrieved Jan 14, 2021 from https://www.reuters.com/ article/us-health-coronavirus-new-mexico/ quarantine-or-not-tourists-still-flock-to-newmexico-idUSKCN24G16P

37. Steens, A., De Blasio, B. F., Veneti, L., Gimma, A., Edmunds, W. J., Van Zandvoort, K., Robberstad, B. (2020). Poor selfreported adherence to COVID-19-related quarantine/isolation requests, Norway, April 
to July 2020. Eurosurveillance, 25(37), 1-6. https://doi.org/10.2807/1560-7917. ES.2020.25.37.2001607

38. Burn-Murdoch, J., \& Neville, S. (2020). Low UK isolation rates raise worries of virus spreading. Financial Times. Retrieved Jan 14, 2021 from https://www.ft.com/content/ d214ef31-7a5c-4bb5-894f-17c7057ab999

39. Williams, S. N., Armitage, C. J., Tampe, T., \& Dienes, K. (2020). Public perceptions and experiences of social distancing and social isolation during the COVID-19 pandemic: A UK-based focus group study. MedRxiv, 2020.04.10.20061267. https://doi. org/10.1101/2020.04.10.20061267

40. Jung, E., Takahashi, K., Watanabe, K., de la Rosa, S., Butz, M. V., Bülthoff, H. H., \& Meilinger, T. (2016). The Influence of Human Body Orientation on Distance Judgments. Frontiers in Psychology, 7, 217. https://doi. org/10.3389/fpsyg.2016.00217

41. Novelli, D., Drury, J., Reicher, S., \& Stott, C. (2013). Crowdedness mediates the effect of social identification on positive emotion in a crowd: A survey of two crowd events. PLoS ONE, 8(11), e78983. doi:10.1371/journal. pone.0078983

42. Hopkins, N., Reicher, S., Stevenson, C., Pandey, K., Shankar, S., \& Tewari, S. (2019). Social relations in crowds: Recognition, validation and solidarity. European Journal of Social Psychology, 49, 1283-1297. doi:10.1002/ejsp.2586

43. Takahashi, R. (2020). Tokyo faces another critical weekend as daily infection rate hits record high. Thejapantimes. Retrieved July 26, 2020 from https://www.japantimes.co.jp/ news/2020/07/24/national/tokyo-infectionrate-hits-record-high/. Accessed 26 July 2020

44. ABC. (2020). Victorian coronavirus outbreak at Melbourne hotel after security guards reportedly breached physical-distancing guidelines. Retrieved July 24, 2020 from https://www.abc.net.au/news/2020-06-19/ coronavirus-cases-in-victoria-rise-outbreakstamford-plaza-hotel/12372188.

45. Ag Ahmed, M. A., Ly, B. A., Millimouno, T. M., Alami, H., Faye, C. L., Boukary, S., ... Doumbia, S. (2020). Willingness to comply with physical distancing measures against COVID-19 in four African countries. BMJ
Global Health, 5(9), e003632. https://doi. org/10.1136/bmjgh-2020-003632

46. Saluja, G. (2020). We're not all in this together - Messages about social distancing need the right cultural fit. The Conversation. Retrieved July 28, 2020 from https://theconversation. com/were-not-all-in-this-together-messagesabout-social-distancing-need-the-rightcultural-fit-135427.

47. Joachim, G., \& Acorn, S. (2000). Stigma of visible and invisible chronic conditions. Journal of Advanced Nursing, 32(1):243-248. https:// doi.org/10.1046/j.1365-2648.2000.01466.x

48. Pager, D., \& Shepherd, H. (2008). The sociology of discrimination: Racial discrimination in employment, housing, credit, and consumer markets. Annual Review of Sociology, 34(1):181-209. https://doi. org/10.1146/annurev.soc.33.040406.131740

49. Siu, JY-M. (2016.) Qualitative study on the shifting sociocultural meanings of the facemask in Hong Kong since the severe acute respiratory syndrome (SARS) outbreak: implications for infection control in the postSARS era. International Journal for Equity in Health, 15, 73. https://doi.org/10.1186/ s12939-016-0358-0

50. Burgess, A., \& Horii, M. (2012). Risk, ritual and health responsibilisation: Japan's 'safety blanket' of surgical face mask-wearing. Sociology of Health \& IIIness, 34, 1184-1198. doi:10.1111/j.1467-9566.2012.01466.x

51. Christiani, L. , Clark, C., Greene, S., Hetherington, M. J., \& Wager, E. (2020). Masks and racial stereotypes in a Pandemic: The case for surgical masks. SSRN. Retrieved July 28, 2020 from https://ssrn. com/abstract $=3636540$.

52. Goldberg, M. H., Gustafson, A., Maibach, E. W., Ballew, M. T., Bergquist, P., Kotcher, J. E., Marlon, J. R., Rosenthal, S. A., \& Leiserowitz, A. (2020). Mask-wearing increased after a government recommendation: A natural experiment in the U.S. during the COVID-19 pandemic. Frontiers in Communication, 5, 44. doi: 10.3389/fcomm.2020.00044

53. McKelvey, T. (2020). Coronavirus: Why are Americans so angry about masks? BBC. Retrieved July 28, 2020 from https://www. bbc.com/news/world-us-canada-53477121.

54. Chen, X., Ran, L., Liu, Q., Hu, Q., Du, X., \& 
Tan, X. (2020). Hand hygiene, mask-wearing behaviors and its associated factors during the COVID-19 epidemic: A cross-sectional study among primary school students in Wuhan, China. International Journal of Environmental Research and Public Health, 17(8). https://doi.org/10.3390/ijerph17082893

55. WHO. (2009). WHO guidelines on hand hygiene in health care: First global patient safety challenge clean care is safer care. Retrieved 28 July, 2020 from https://www. ncbi.nlm.nih.gov/books/NBK143998/.

56. Tang, K. H. D. (2020). Hydroelectric dams and power demand in Malaysia: A planning perspective. Journal of Cleaner Production, 252, 119795. https://doi.org/https://doi. org/10.1016/j.jclepro.2019.119795

57. Tang, K.H.D., \& Angela, J. (2019). Phytoremediation of crude oil-contaminated soil with local plant species. IOP Conference Series: Materials Science and Engineering, 495, 12054. https://doi.org/10.1088/1757899x/495/1/012054

58. Tang, K. H. D. (2020). Anticipations for and Perceived Barriers of Development among the Sarawak's Highlanders. Pertanika Journal of Social Sciences \& Humanities, 28(2). 